\title{
The Impact of Information Signals on Market Prices when Agents have Non-linear Trading Rules
}

\author{
C. Kyrtsou \\ University of Macedonia
}

Anastasios G. Malliaris

Loyola University Chicago, tmallia@luc.edu

Follow this and additional works at: https://ecommons.luc.edu/business_facpubs

Part of the Business Commons

\section{Author Manuscript}

This is a pre-publication author manuscript of the final, published article.

\section{Recommended Citation}

Kyrtsou, C. and Malliaris, Anastasios G.. The Impact of Information Signals on Market Prices when Agents have Non-linear Trading Rules. Economic Modeling, 26, 1: 167-176, 2009. Retrieved from Loyola eCommons, School of Business: Faculty Publications and Other Works, http://dx.doi.org/10.1016/ j.econmod.2008.06.008

This Article is brought to you for free and open access by the Faculty Publications and Other Works by Department at Loyola eCommons. It has been accepted for inclusion in School of Business: Faculty Publications and Other Works by an authorized administrator of Loyola eCommons. For more information, please contact ecommons@luc.edu.

\section{c) (i) $\ominus$}

This work is licensed under a Creative Commons Attribution-Noncommercial-No Derivative Works 3.0 License. (c) Elsevier 2009. 
The impact of information signals on market prices when agents have nonlinear trading rules.

\author{
by Catherine KYRTSOU ${ }^{(1)}$ and A. G. MALLIARIS ${ }^{(2)}$ \\ ${ }^{(1)}$ University of Macedonia \\ Department of Economics \\ Egnatia Street 156, \\ 54006, Thessaloniki, GREECE \\ e-mail: ckyrtsou@uom.gr \\ (2) Department of Economics and Finance \\ School of Business Administration \\ Loyola University Chicago \\ 1 East Pearson Street \\ Chicago, IL 60611, USA \\ e-mail: tmallia@luc.edu
}

Corrected current draft: May 2008: This paper has been accepted for publication on June 25, 2008 in ECONOMIC MODELLING. 


\title{
The impact of information signals on market prices when agents have non- linear trading rules.
}

\begin{abstract}
Several methods have been developed for filtering seasonal influences and extreme returns in financial and economic time series. The theoretical support for these approaches is rather questionable since it focuses on the effects of shocks on prices and not on their sources. Removing such effects modifies the true generating system of market dynamics because of the non-proportional character of nonlinearity. Thus, taking into account that the underlying process of economic time series is highly non-linear we cannot be certain a priori what the impact of new information will be on the dynamic structure of a system. The main contribution of this paper is to demonstrate using the methodology of simulations the eventual distortions in time series data arising from the arrival of news when agents' follow non-linear trading strategies. We argue that if news can really modify the dynamical behaviour of a system, then the methodology of filtering exogenous distortions needs to be re-examined.
\end{abstract}

Key words: information signals, economic modelling, non-linear trading strategies, Heteroskedastic Mackey-Glass model.

JEL classification: C15, C22, C52, G14 


\section{The impact of information signals on market prices when agents have non- linear trading rules.}

\section{Introduction}

Numerous empirical studies have analyzed the identification and nature of the underlying process of an economic system, as well as the influence of information on financial time series. The standard financial theory of efficient markets assumes identical investors having rational expectations of future stock prices who instantaneously discount all market information into these prices. This means that there are no opportunities for speculative profit, and both trading volume and price volatility are not serially correlated.

In reality, financial markets are highly complex systems as documented in Kyrtsou and Terraza (2002), and Kyrtsou, et al. (2004), among others. Such complexity may be attributed to numerous factors such as the reaction to public and private information presented in Vega (2006) and Daniel and Titman (2006), the role of investors' behaviour recently discussed in Hirshleifer, et al. (2006) and Bernhardt et al. (2006) or other factors. Complexity in commodity futures and currency markets is presented in Corazza et al. (1997) and Corazza and Malliaris (2002) respectively.

Regarding all available information we observe that it cannot be perfect. Often, information is rather inadequate, that is, noisy, insufficient and costly. Furthermore, traders have bounded rationality, that is, even if they receive all relevant economic information they are not able to interpret it correctly and they make mistakes in their economic reasoning.

To understand the inherent dynamics of financial markets, one needs to focus on a relevant question raised by Malliaris and Stein (1999) who ask: "If price changes are induced by changes in information, can information concerning the shocks in fundamental factors explain the magnitude of the observed price volatility? Or is the variance of price changes due to other factors?". In fact, if the information is the cause of market anomalies, then why can we observe 
excess returns occurring with little or no news? (Curlet et al., 1989). Indeed, "trajectories can easily exhibit complex dynamics, independently of any arrival of news" (Franke and Sethi (1998)).

As Lee et al., (2002) have pointed out, the important factor in market fluctuations is not the events themselves, but the human reactions to those events. The kind of complexity in agents' behavioural rules will determine the nature of the underlying dynamics of price series. The difference in conditional volatility for stocks is due to the amount and quality of information as well as the mechanism the agents follow for making decisions. Such a mechanism accounts for the arrival of information and its incorporation into prices.

The information can arrive in the market randomly or follow a periodic pattern. Depending on the nature of the mechanism that determines the arrival of news, information can produce various kinds of stylised facts in the market. For example endogenous and exogenous shocks can affect in a dissimilar manner the market and cause unequal disturbances. The intensity of such shocks will depend on the particular characteristics of investors who receive the information, interpret it and finally incorporate it into asset prices via investment strategies. As Kyrtsou (2005a) has demonstrated, it is possible to observe departures of prices from their fundamental value, when assuming that the fundamental value is directly perturbed by exogenous news in an artificial market framework.

Several methods have been developed for filtering financial and economic series from "acquired" structures such as seasonal structures and extreme observations as in Bollerslev and Ghysels (1996), Beller and Nofsinger (1998), Burridge and Taylor (1999), Balke and Fomby (1994), Van Dijk et al. (1999) and Franses et al. (2004). Nonetheless, this unidimensional analysis of the effects of shocks on prices could be found inappropriate when the series under study present more complicated dynamics than the traditional theory of Efficient markets suggests. The appearance of nonlinear structures in association with the non-proportional character of non-linearity, (i.e. the effect is not proportional to its cause) doubt the effectiveness of any removal procedure of outliers or seasonality, especially when the investigator is interested in finding the true generating system of economic dynamics. Based on the above and 
taking into account that the underlying process of economic series is highly non-linear (Kyrtsou and Vorlow (2005), Kyrtsou and Serletis (2006), and Kyrtsou and Labys (2006, 2007), Kyrtsou et al. (2006)), we cannot be sure a priori what the impact of new information on the dynamic structure of the system will be.

The main objective of this article is to identify, using simulations, the effects of incorporating periodic or irregular information into linear and non-linear time series. If news can modify the dynamical behaviour of the system, that is, the structure of the attractor and its dimensionality and induce "acquired" structures, then many questions arise about the efficiency of different models for filtering such effects.

The remainder of the paper proceeds as follows. Section 2 presents different models describing possible trading rules, including the Kyrtsou and Terraza (2003) process. Section 3 discusses the results of simulation experiments, while the last section provides some concluding remarks.

\section{Linear and non-linear trading rules}

The increasing number of econometric studies and empirical results supporting the existence of non-linear structures has led financial economists to the conclusion that the linear hypothesis is not inherent to the economic system, but rather it has been used for reasons of analytic simplicity.

When dealing with financial markets, inherent instability is significant and thus it is simplistic to argue about linear cause and effect relationships. It is more realistic to consider that relationships among economic agents are non-linear and are driven by non-linear trading rules. The nature of traders' beliefs is a crucial point in our study since Kurz, et al. (2003) show that diversity in beliefs can explain why different interpretations arise given the same information. These authors propose that the true law of motion of an economy follows nonlinear complex dynamics that is unknown. Agents have long historical data generated by such a law of motion and by analyzing such data they form appropriate trading strategies. In contrast to a rational expectations equilibrium where the true law of motion is common knowledge, agents in the 
Kurz, et al. (2003) paper form beliefs based on the available data and their behaviour reduces to rational expectations only as a special case.

As it is emphasized by Franke and Sethi (1998) "the source of the erratic ...(highdimensional) price trajectories can be identified in the formulation of chartists' demand for the asset", which is non-linear. Noise traders (or chartists) can drive prices away from their fundamental values. Besides, these noise traders, according to Shefrin and Statman (1994) "distort the mean-variance efficient frontier, thereby creating abnormal returns to particular securities". They also commit errors when new information arrives in the market. Thus it is quite possible that less important information creates high volatility when it is incorporated into prices via a non-linear (noise) trading rule.

According to Yang and Satchell (2003) "the market in the absence of technical traders would reach the fundamental equilibrium with fluctuations only due to exogenous shocks". This means that exogenous information has been incorporated into prices as it was; so prices do not reflect any other distortions due primarily to endogenous trading. Nevertheless, "in the presence of technical traders," having non-linear strategies, "fluctuations off the fundamental equilibrium can be systematically and endogenously induced by the feedback effect brought about the technical analysis".

To demonstrate the informative power of the non-linear trading rules we compare the following agent's strategies.

1. A linear strategy: $\mathrm{X}_{\mathrm{t}}=\mathrm{aX} \mathrm{X}_{\mathrm{t}-1}$

2. A non-linear strategy, the chaotic logistic equation: $\mathrm{X}_{\mathrm{t}}=\mathrm{bX} \mathrm{X}_{\mathrm{t}-1}\left(1-\mathrm{X}_{\mathrm{t}-1}\right)=\mathrm{bX} \mathrm{t}-1-b X_{t-1}^{2}$

3. A second non-linear strategy, the chaotic Mackey-Glass equation: $X_{t}=\alpha \frac{X_{t-\tau}}{1+X_{t-\tau}^{c}}-\delta X_{t-1}$ with $\mathrm{c}=2$ and $\tau=1$, where $\mathrm{c}$ is a constant and $\tau$ the delay. For these values of parameters we can obtain $\mathrm{X}_{\mathrm{t}}=\mathrm{X}_{\mathrm{t}-1}\left(\alpha \frac{1}{1+\mathrm{X}_{\mathrm{t}-1}^{2}}-\delta\right)$.

As it can be seen, only for the two non-linear trading strategies, the amplitude of stock prices movements $\left(\mathrm{X}_{\mathrm{t}-1}^{2}\right)$ influences investors' expectations for future price fluctuations. The impact of 
$\mathrm{X}_{\mathrm{t}-1}^{2}$ on $\mathrm{X}_{\mathrm{t}}$ in the case of the second rule is additive while for the third the impact is multiplicative.

Non-linear trading rules seem to be a more efficient way to model the observed behaviour, since the impact of new information both on mean and variance dynamics is analysed by the agents' expectations mechanism. In this manner, investors with non-linear trading strategies can profit from their ability to better understand the market.

The knowledge of the underlying dynamics is also important because we can specify the way that exogenous perturbations such as noise and seasonality are amplified in the system. To describe this amplification of information we simulate the previous three models perturbed by noise with and without exogenous information.

The choice of the Mackey-Glass and logistic equations is intentional. In a recent series of papers (Kyrtsou and Terraza (2003), Kyrtsou (2005b, 2006), and Kyrtsou and Serletis (2006)), evidence is provided that heterogeneity in agents' expectations, large shocks and market complexity decrease the power of traditional stochastic models. On the basis of simulation experiments Kyrtsou and Terraza (2003) explain how simple short-term autocorrelated series can be generated by high-dimensional chaotic models, like the heteroskedastic Mackey-Glass process.

The noisy version of the Mackey-Glass process in discrete time offers several advantages, especially when financial series are tested. With a slight modification in the values of parameters $\mathrm{c}$ and $\tau$ it is possible to produce extremely rich dynamics that mimic properties of real returns series. Moreover, the noisy Mackey-Glass model captures feedback behaviour in a market where heterogeneous investors interact. A recent extension of the initial model developed by Kyrtsou (2006), called the Generalized Noisy Mackey-Glass, which also includes the Logistic equation, filters separately positive and negative feedback strategies.

High-dimensional non-linearity in mean is an interesting feature of asset returns series. Researchers working on Garch modelling and risk analysis have ignored its impact on volatility dynamics. Nevertheless, Kyrtsou and Terraza (2008) have demonstrated that taking into account 
chaotic non-linearity in the mean of French assets with the use of the heteroskedastic MackeyGlass model, improves Value-at-Risk estimations.

Since the role of endogenous instability is crucial for the determination of market prices, appropriate trading strategies should be considered in order to arrive to realistic conclusions.

\section{Simulations experiments and empirical results}

In this section the following models are used in our simulations experiments. The values of parameters have been chosen based on the simulation study performed by Kyrtsou and Terraza (2003). For these specific values, the nonlinear models have the properties we are usually observed in real economic and financial time series.

- An AR(1) model with $\phi_{1}=0.5, \mathrm{X}_{0}=1.2$ (hereafter AR).

$$
X_{t}=\phi_{1} X_{t-1}+\varepsilon_{t} \quad \varepsilon_{t} \sim N(0,1)
$$

- A logistic equation with and without noise and $\mathrm{b}=3.8, \mathrm{X}_{0}=1.2$ (hereafter LogEq without noise, $\operatorname{LogEqN}$ with white noise and $\log \mathrm{EqA}$ with heteroskedastic noise).

$$
\mathrm{X}_{\mathrm{t}}=\mathrm{bX} \mathrm{t}-1\left(1-\mathrm{X}_{\mathrm{t}-1}\right)
$$

- Mackey-Glass $^{1}$ equations with and without noise and $\tau=1, c=2,10,30, \alpha=2.1, \delta=0.05$, $\mathrm{a}_{0}=0.2, \mathrm{a}_{1}=0.6, \mathrm{X}_{0}=1.2$.

1. $\mathrm{X}_{\mathrm{t}}=\alpha \frac{\mathrm{X}_{\mathrm{t}-1}}{1+\mathrm{X}_{\mathrm{t}-1}^{10}}-\delta \mathrm{X}_{\mathrm{t}-1}$ (hereafter Mac10)

2. $\mathrm{X}_{\mathrm{t}}=\alpha \frac{\mathrm{X}_{\mathrm{t}-1}}{1+\mathrm{X}_{\mathrm{t}-1}^{10}}-\delta \mathrm{X}_{\mathrm{t}-1}+\varepsilon_{\mathrm{t}}$ with $\varepsilon_{\mathrm{t}} \sim \mathrm{N}(0,1)$ (hereafter Mac10n)

3. $\mathrm{X}_{\mathrm{t}}=\alpha \frac{\mathrm{X}_{\mathrm{t}-1}}{1+\mathrm{X}_{\mathrm{t}-1}^{10}}-\delta \mathrm{X}_{\mathrm{t}-1}+\varepsilon_{\mathrm{t}}$ with $\varepsilon_{\mathrm{t}} \sim \mathrm{N}\left(0, \mathrm{~h}_{\mathrm{t}}\right)$ and $\mathrm{h}_{\mathrm{t}}=\mathrm{a}_{0}+\mathrm{a}_{1} \varepsilon_{\mathrm{t}-1}^{2}$ (hereafter Mac10a)

4. $\quad \mathrm{X}_{\mathrm{t}}=\alpha \frac{\mathrm{X}_{\mathrm{t}-1}}{1+\mathrm{X}_{\mathrm{t}-1}^{30}}-\delta \mathrm{X}_{\mathrm{t}-1}$

(hereafter Mac30)

\footnotetext{
${ }^{1}$ For more details about Mackey-Glass equation with normal and heteroskedastic errors see Kyrtsou and Terraza (2003) and Kyrtsou (2006). For a multivariate setting see Kyrtsou and Labys (2006, 2007), Hristu-Varsakelis and Kyrtsou (2008), Kyrtsou and Vorlow (2009).
} 
5. $\mathrm{X}_{\mathrm{t}}=\alpha \frac{\mathrm{X}_{\mathrm{t}-1}}{1+\mathrm{X}_{\mathrm{t}-1}^{30}}-\delta \mathrm{X}_{\mathrm{t}-1}+\varepsilon_{\mathrm{t}}$ with $\varepsilon_{\mathrm{t}} \sim \mathrm{N}(0,1)$

(hereafter Mac30n)

6. $\mathrm{X}_{\mathrm{t}}=\alpha \frac{\mathrm{X}_{\mathrm{t}-1}}{1+\mathrm{X}_{\mathrm{t}-1}^{30}}-\delta \mathrm{X}_{\mathrm{t}-1}+\varepsilon_{\mathrm{t}}$ with $\varepsilon_{\mathrm{t}} \sim \mathrm{N}\left(0, \mathrm{~h}_{\mathrm{t}}\right)$ and $\mathrm{h}_{\mathrm{t}}=\mathrm{a}_{0}+\mathrm{a}_{1} \varepsilon_{\mathrm{t}-1}^{2}$

(hereafter Mac30a)

7. $\mathrm{X}_{\mathrm{t}}=\alpha \frac{\mathrm{X}_{\mathrm{t}-1}}{1+\mathrm{X}_{\mathrm{t}-1}^{2}}-\delta \mathrm{X}_{\mathrm{t}-1}+\varepsilon_{\mathrm{t}}$ with $\varepsilon_{\mathrm{t}} \sim \mathrm{N}(0,1)$

(hereafter Mac2n)

8. $\mathrm{X}_{\mathrm{t}}=\alpha \frac{\mathrm{X}_{\mathrm{t}-1}}{1+\mathrm{X}_{\mathrm{t}-1}^{2}}-\delta \mathrm{X}_{\mathrm{t}-1}+\varepsilon_{\mathrm{t}}$ with $\varepsilon_{\mathrm{t}} \sim \mathrm{N}\left(0, \mathrm{~h}_{\mathrm{t}}\right)$ and $\mathrm{h}_{\mathrm{t}}=\mathrm{a}_{0}+\mathrm{a}_{1} \varepsilon_{\mathrm{t}-1}^{2}$

(hereafter Mac2aex)

9. $\mathrm{X}_{\mathrm{t}}=\alpha \frac{\mathrm{X}_{\mathrm{t}-1}}{1+\mathrm{X}_{\mathrm{t}-1}^{2}}-\delta \mathrm{X}_{\mathrm{t}-1}+\varepsilon_{\mathrm{t}}$ with $\varepsilon_{\mathrm{t}} \sim \mathrm{N}\left(0, \mathrm{~h}_{\mathrm{t}}\right), \mathrm{h}_{\mathrm{t}}=\mathrm{a}_{0}+\mathrm{a}_{1} \varepsilon_{\mathrm{t}-1}^{2}$, and $\varepsilon_{\mathrm{t}}=\varepsilon_{\mathrm{t}-1}+\varepsilon_{\mathrm{t}-2} \quad$ (hereafter Mac2aen)

After 1000 replications for each model we obtain simulated series of 4096 observations. The sample statistics of these series are given in Table 1. When a dummy representing the arrival of new information is added to the series, sample statistics change completely. We did not study the properties of the deterministic part of the AR(1) model, since for $\mathrm{X}_{0}=1.2, \mathrm{X}_{\mathrm{t}}$ converges to the fixed point $\bar{X}=1$. With the same justification we exclude from the simulation experiment the deterministic part of the Mac2n model; for an initial value equal to $1.2, \mathrm{X}_{\mathrm{t}}$ converges to its equilibrium point.

Looking at Table 1, we observe that information signals do not modify the normality of the AR(1) model. On the contrary, in the case of $\operatorname{LogEq}, \operatorname{LogEqN}$ and $\log \mathrm{EqA}$, both periodic and irregular perturbations increase the non-normality. Concerning the different Mackey-Glass processes, the obtained results are more complex. In the deterministic cases, Mac10 and Mac30, information increases kurtosis and Jarque-Bera. In the stochastic cases, Mac2n, Mac2aex, Mac2aen, Mac10n, Mac10a, Mac30n and Mac30a, a dual effect emerges: (1) Exogenous information is lost in the structure of white noise and so globally we do not have significant modifications on kurtosis and Jarque-Bera; (2) Interactions between exogenous signals and heteroskedastic noise could stabilize the system. For example, for S_Mac2aex kurtosis and Jarque-Bera were reduced from 4.898 to 4.428 and from 657.7 to 399.9 respectively. 
The dynamic behaviour of the linear and non-linear trading rules before and after the influence of information is described in Figures 1-13. The three attractors of the linear stochastic model (Figure 1) are identical. For the non-linear deterministic models, the addition of information signals leads to systems with multiple attractors. The dual effect that we described previously, can be clearly identified in Figures 6, 7, 9, 10, 11, 12, and 13.

In Table 2, we report the results from the estimation of the most representative simulated series. For example, estimations for LogEqA are not included in Table 2, since they do not significantly differ from the estimations of the LogEqN model. The main objective is to study the stability of the coefficients of the different models. If the estimated values are similar with those used in the simulation experiments, then the dynamic structure of the system remains unchangeable even if new information perturbs the market. Otherwise, information signals can affect the underlying structure.

As is shown in Table 2, on the one hand the incorporation of either periodic or irregular information into $\mathrm{AR}(1)$ does not modify the coefficient $\phi_{1}$. In all cases it is close to 0.5 (value used in our simulations). On the other hand, exogenous information can drastically affect the structure of the non-linear models. For LogEqN the coefficient $b$ is equal to 0.51 in the case of periodic signals (i.e. S_LogEqN) and 0.27 in the case of irregular signals (i.e. S2_LogEqN). Both values are far from 3.8. For Mac2n, $\alpha$ is equal to 1.65 and 2.06 , while $\delta$ is equal to -0.11 and 0.02 in the cases of periodic (i.e. S_Mac2n) and irregular signals (i.e. S2_Mac2n) respectively. These values are also far from the initial values: 2.1 for $\alpha$ and 0.05 for $\delta$.

Regarding deterministic dummies, the results can be classified in two categories. When the mechanism is high-dimensional, i.e either pure stochastic or stochastic chaotic, we obtain statistical significance only for $D_{1}, D_{2}$, and in a few cases also for $D_{5}$. In contrast, when the generating mechanism is low-dimensional, i.e. chaotic, statistical significance is detected for the five dummies. 


\section{Implications}

The main point of the paper is to present by simulation experiments the impact on trading rules arising from the arrival of new information in the market when these rules follow non-linear dynamics. The empirical findings provide clear evidence that the incorporation of exogenous information into a series generated by a non-linear mechanism has a direct impact on the dynamic structure of the system itself, while strong seasonal structures appear as long as the system exhibits low-dimensional non-linear dynamics.

Linear systems have the convenient property that smooth changes in their parameters lead to smooth changes in the behaviour of the trajectories. The situation when the system is non-linear is quite different. The laws of motion of the system change as the system moves in the state space. This inherent complexity could explain why exogenous information in a non-linear market can produce unexpected results. Thus, when new signals invade the market, it is very difficult to predict the price evolution if the investors' trading rules are non-linear.

The significance of all seasonal dummies only in the case of low-dimensional non-linear trading rules indicates that as underlying complexity increases obtained results change dramatically. Additional empirical work is required in order to investigate whether and under which conditions deviations of highly complex prices can be isolated.

In conclusion, our work demonstrates that when agents follow non-linear trading rules, the arrival of new information can cause high volatility and instability in financial markets. Such high volatility and instability do not occur in simulations when trading rules are modelled to be linear. Thus, further research on the nature of nonlinear investment strategies is needed to solve the relevant problems about the causes of instability and high volatility in financial markets. 
Table 1: Sample statistics and autocorrelation of the simulated series ${ }^{2}$.

\begin{tabular}{|c|c|c|c|c|c|}
\hline Models & Kurtosis & Skewness & Jarque-Bera & $Q(12)^{1}$ & $Q(24)^{1}$ \\
\hline$A R(1)$ & 2.93 & 0.01422 & 0.9345 & $1233(0.000)$ & $1254(0.000)$ \\
\hline$S \_A R(1)$ & 2.937 & 0.055 & 2.794 & $917.25(0.000)$ & $1077.9(0.000)$ \\
\hline$S 2 \_A R(1)$ & 2.94 & 0.043 & 1.869 & $1125.2(0.000)$ & $1145(0.000)$ \\
\hline $\log E q$ & 1.978 & -0.5157 & 359.63 & $2054.2(0.000)$ & $2081.7(0.000)$ \\
\hline$S \_\log E q$ & 3.0152 & 0.8514 & 494.89 & $6447.3(0.000)$ & $12243(0.000)$ \\
\hline$S 2 \_\log E q$ & 5.656 & 0.9718 & 1849.27 & $932.66(0.000)$ & $1010.9(0.000)$ \\
\hline $\log E q N$ & 1.8812 & -0.4397 & 345.619 & $1619.2(0.000)$ & $1638.5(0.000)$ \\
\hline$S \_\log E q N$ & 3.006 & 0.819 & 458.49 & $5774.5(0.000)$ & $11115(0.000)$ \\
\hline$S 2 \_\log E q N$ & 5.233 & 0.8743 & 1373.05 & $693.09(0.000)$ & $752.86(0.000)$ \\
\hline $\log E q A$ & 1.847 & -0.426 & 350.65 & $1791.4(0.000)$ & $1802.7(0.000)$ \\
\hline$S \_\log E q A$ & 2.99 & 0.838 & 479.43 & $6089.6(0.000)$ & $11603(0.000)$ \\
\hline$S 2 \_\log E q A$ & 5.262 & 0.922 & 1454.35 & $815.14(0.000)$ & $888.92(0.000)$ \\
\hline $\operatorname{Mac} 2 n$ & 2.699 & 0.0209 & 15.716 & $2076.4(0.000)$ & $2085.1(0.000)$ \\
\hline$S \_M a c 2 n$ & 2.757 & 0.034 & 10.79 & $1681.4(0.000)$ & $1762.8(0.000)$ \\
\hline$S 2 \_M a c 2 n$ & 2.697 & 0.02 & 15.869 & $1991.2(0.000)$ & $1998.6(0.000)$ \\
\hline Mac2aex & 4.898 & 0.2502 & 657.708 & $5655.5(0.000)$ & $5742(0.000)$ \\
\hline S_Mac2aex & 4.428 & 0.275 & 399.9 & $4254.2(0.000)$ & $4499.7(0.000)$ \\
\hline S2_Mac2aex & 4.725 & 0.266 & 556.57 & $5317.3(0.000)$ & $5411.4(0.000)$ \\
\hline Mac2aen & 3.629 & -0.0228 & 67.937 & $3756.7(0.000)$ & $3774.4(0.000)$ \\
\hline S_Mac2aen & 3.539 & 0.0126 & 49.719 & $3042(0.000)$ & $3156.9(0.000)$ \\
\hline S2_Mac2aen & 3.668 & 0.0098 & 76.428 & $3583.9(0.000)$ & $3603.6(0.000)$ \\
\hline Mac10 & 3.2216 & -0.0126 & 8.494 & $5420.4(0.000)$ & $5522.4(0.000)$ \\
\hline S_Mac10 & 29 & 0.21 & 33.24 & $3385.4(0.000)$ & $4134.2(0.000)$ \\
\hline$S 2 \_M a c 10$ & 3.423 & 0.149 & 45.923 & $4478.8(0.000)$ & $4560.1(0.000)$ \\
\hline Mac10n & 2.9071 & 0.0233 & 1.844 & $223.95(0.000)$ & $231.99(0.000)$ \\
\hline S_Mac10n & 2.98 & 0.075 & 3.984 & $252.13(0.000)$ & $355.18(0.000)$ \\
\hline$S 2 \_M a c 10 n$ & 2.94 & 0.044 & 1.9206 & $212.95(0.000)$ & $224.41(0.000)$ \\
\hline Mac10a & 3.769 & 0.032 & 101.72 & $594.93(0.000)$ & $601.97(0.000)$ \\
\hline S_Mac10a & 3.519 & 0.065 & 48.91 & $490.32(0.000)$ & $645.35(0.000)$ \\
\hline$S 2 \_M a c 10 a$ & 3.677 & 0.0647 & 81.22 & $555.44(0.000)$ & $563.78(0.000)$ \\
\hline Mac30 & 3.468 & 0.01615 & 37.674 & $6815.1(0.000)$ & $10137(0.000)$ \\
\hline S_Mac30 & 3.2318 & 0.16 & 26.857 & $4003.8(0.000)$ & $6291.2(0.000)$ \\
\hline S2_Mac30 & 3.503 & 0.1155 & 52.307 & $5622.7(0.000)$ & $8350.5(0.000)$ \\
\hline Mac30n & 3.005 & 0.026 & 0.4814 & $112(0.000)$ & $121.78(0.000)$ \\
\hline S_Mac30n & 3.055 & 0.0639 & 3.3219 & $195.75(0.000)$ & $324.56(0.000)$ \\
\hline S2_Mac30n & 2.987 & 0.0408 & 1.165 & $110.05(0.000)$ & $121.5(0.000)$ \\
\hline Mac30a & 3.487 & -0.0607 & 43.015 & $321.84(0.000)$ & $326.67(0.000)$ \\
\hline S_Mac30a & 3.44 & -0.027 & 33.57 & $343.82(0.000)$ & $506.05(0.000)$ \\
\hline S2_Mac30a & 3.468 & -0.0368 & 38.475 & $295.29(0.000)$ & $302.72(0.000)$ \\
\hline
\end{tabular}

1: Probability is given within parenthesis

2: We note $\mathrm{S}$ when periodical information signal is considered and $\mathrm{S} 2$ for irregular information signal. 


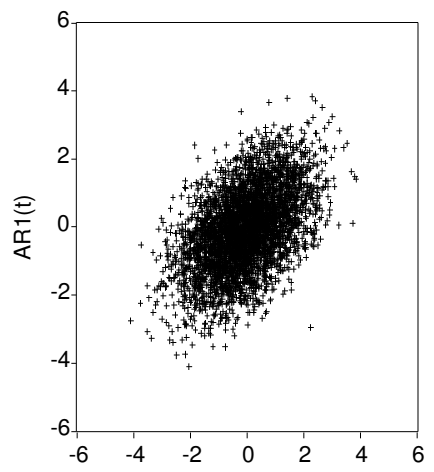

AR1(t-1)

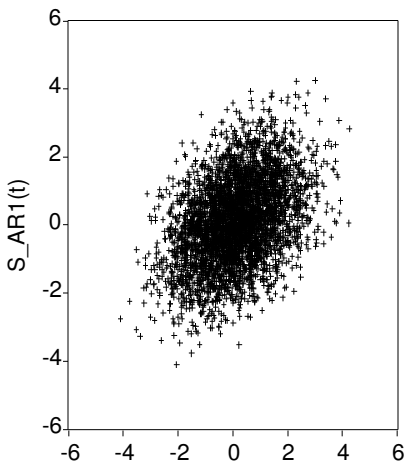

S_AR1(t-1)

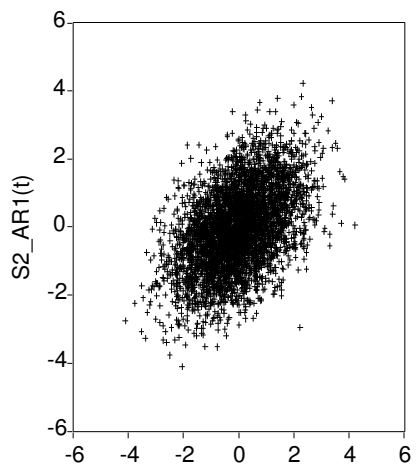

S2_AR1(t-1)

Figures 1a,b,c: Attractors of the AR(1) model with and without information signals
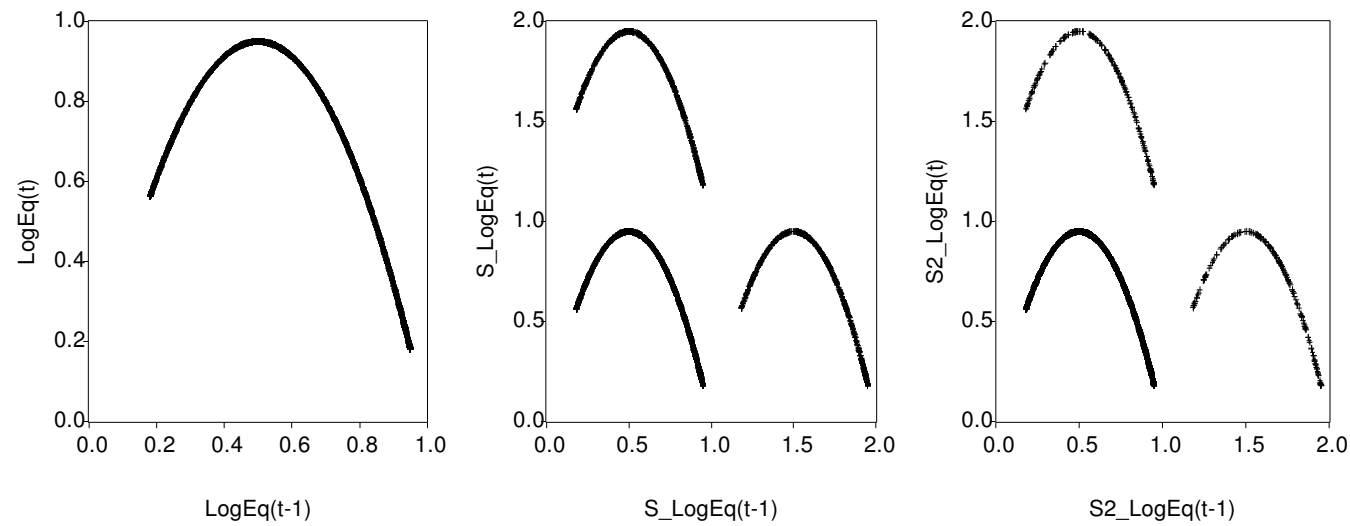

Figures 2a,b,c: Attractors of the LogEq model with and without information signals
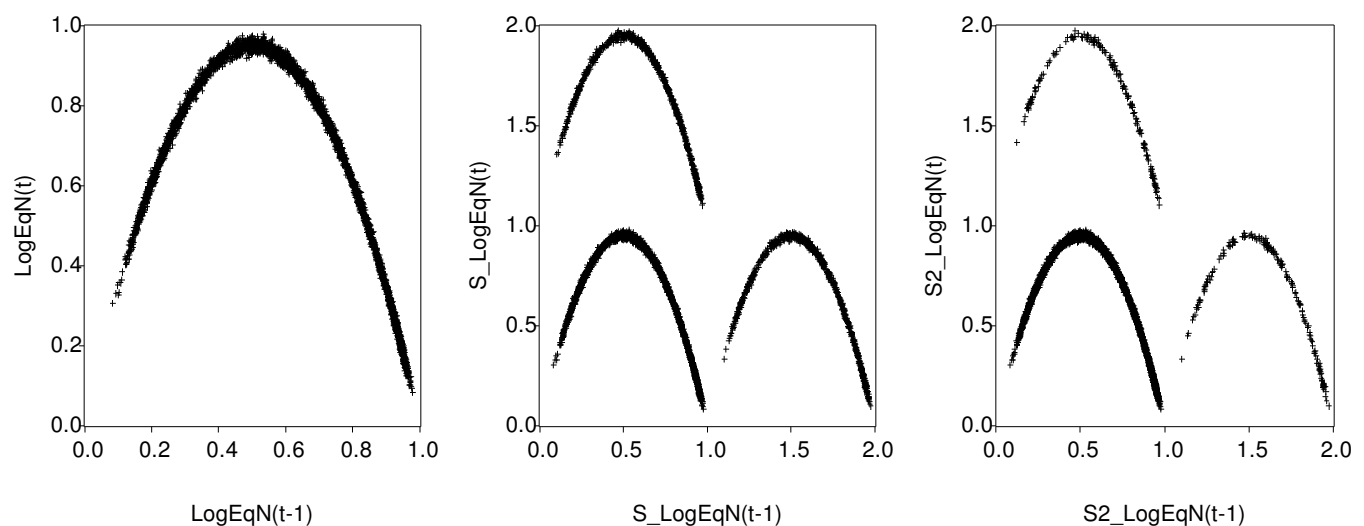

Figures 3a,b,c: Attractors of the $\operatorname{LogEqN}$ model with and without information signals 

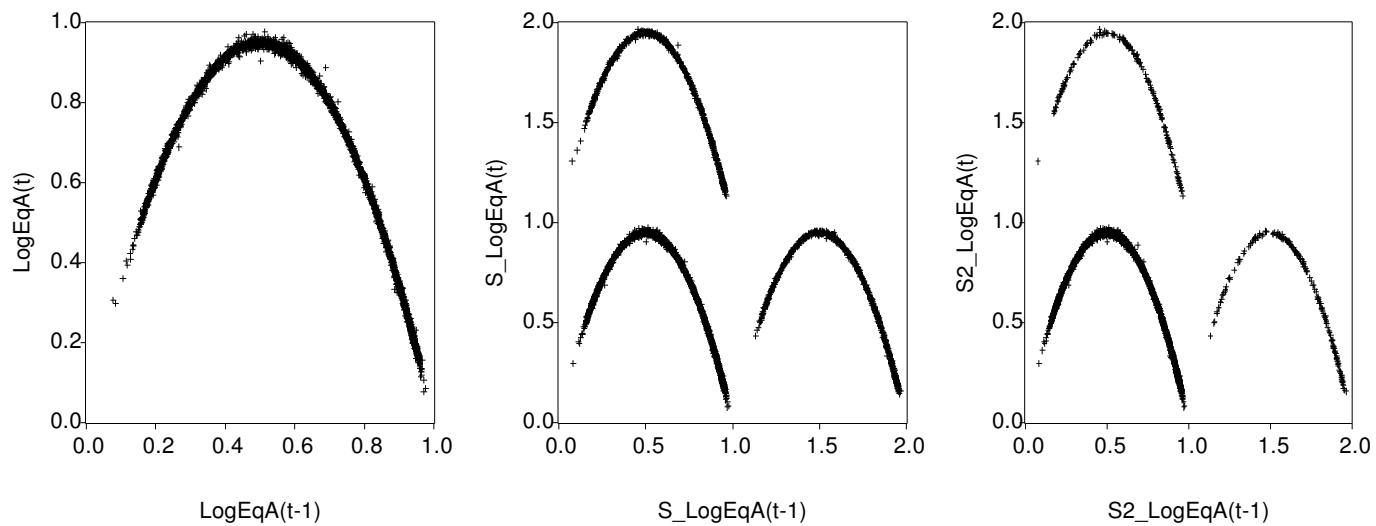

Figures 4a,b,c: Attractors of the $\operatorname{LogEqA}$ model with and without information signals
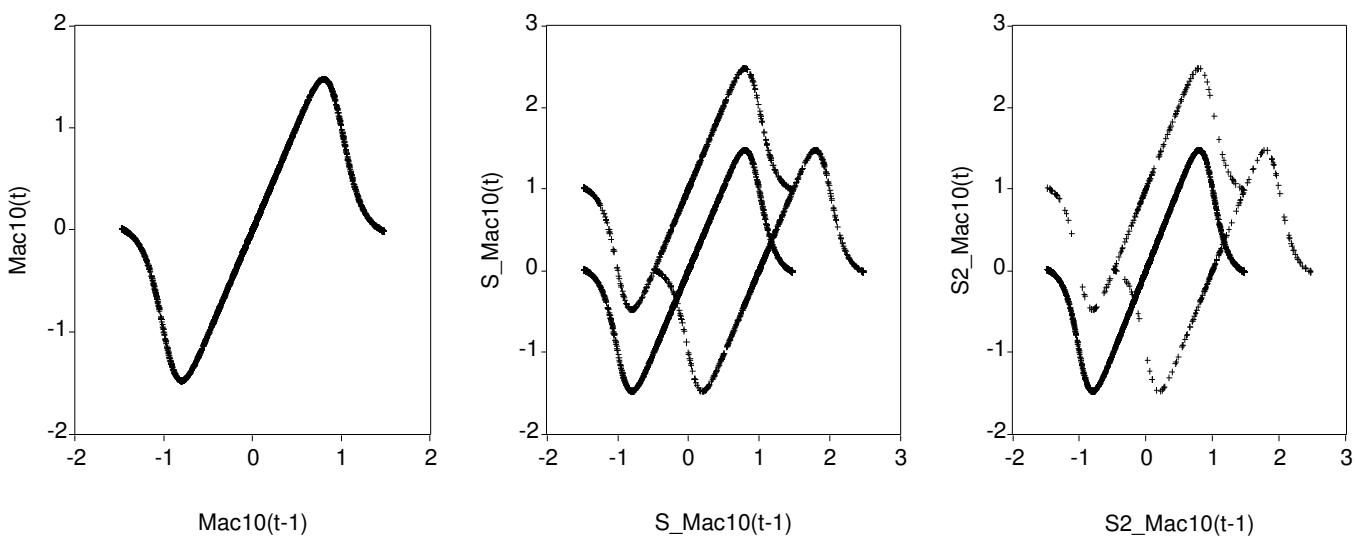

Figures 5a,b,c: Attractors of the Mac10 model with and without information signals
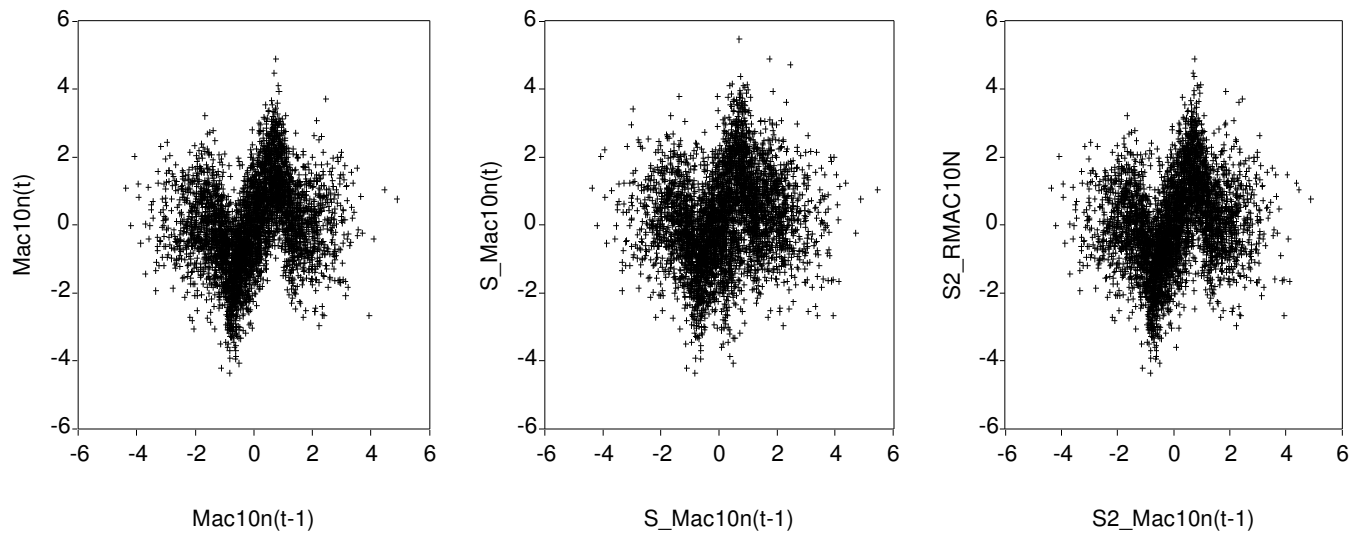

Figures 6a,b,c: Attractors of the Mac10n model with and without information signals 


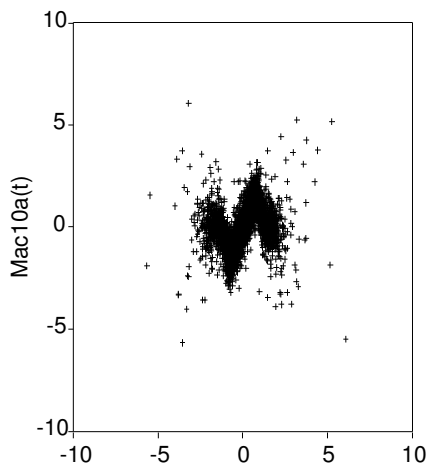

$\operatorname{Mac10a}(\mathrm{t}-1)$

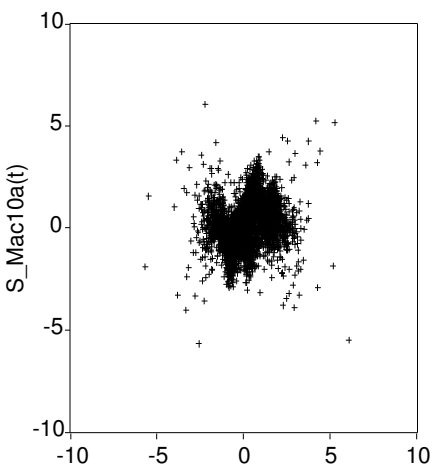

S_Mac10a(t-1)

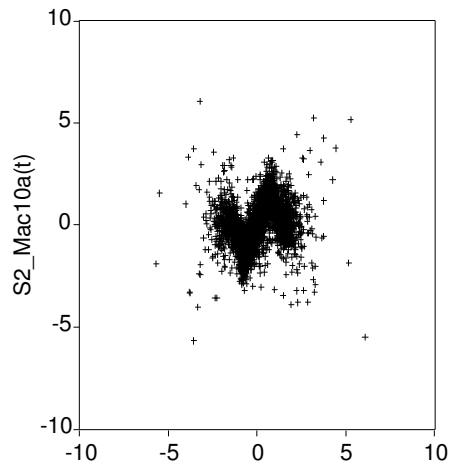

S2_Mac10a(t-1)

Figures 7a,b,c: Attractors of the Mac10a model with and without information signals


Figures 8a,b,c: Attractors of the Mac30 model with and without information signals
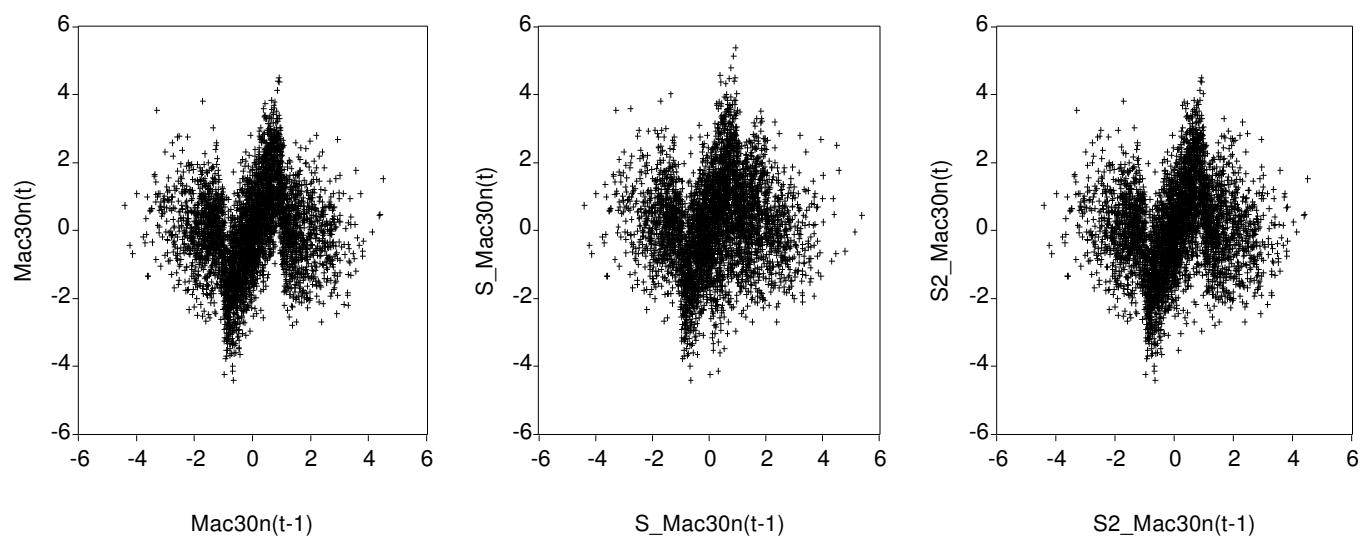

Figures 9a,b,c: Attractors of the Mac30n model with and without information signals 

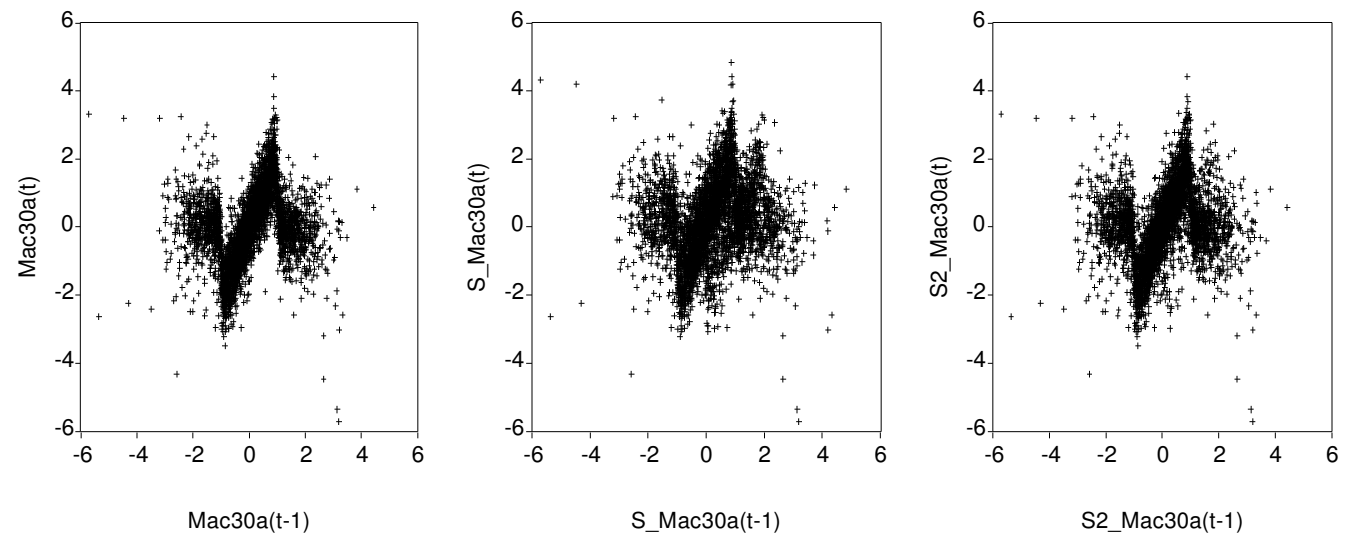

Figures 10a,b,c: Attractors of the Mac30a model with and without information signals
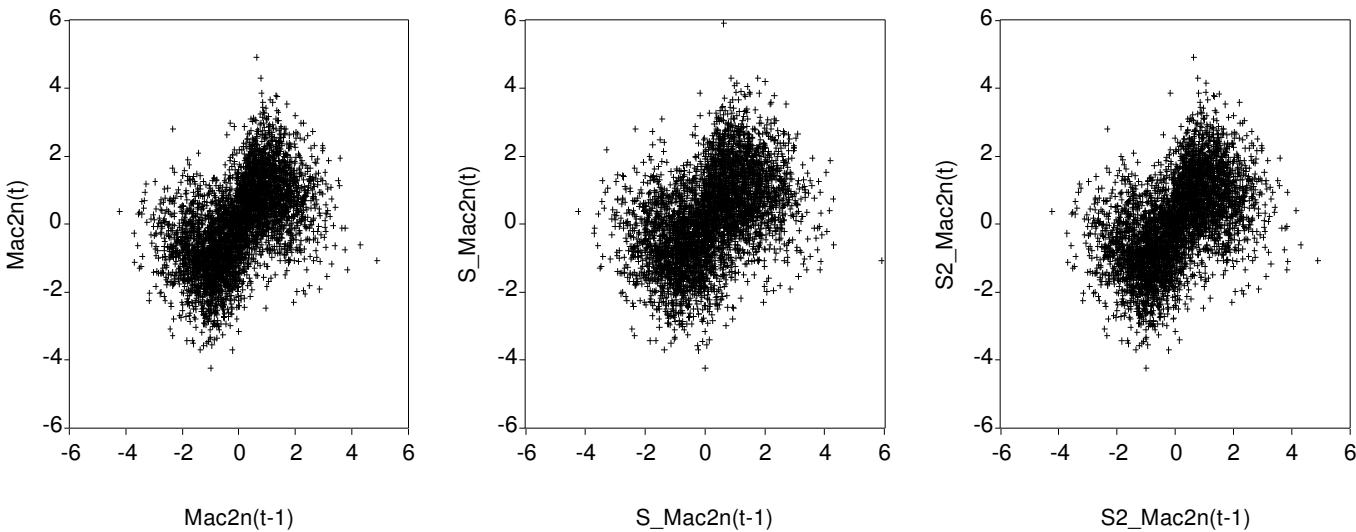

Figures 11a,b,c: Attractors of the Mac2n model with and without information signals
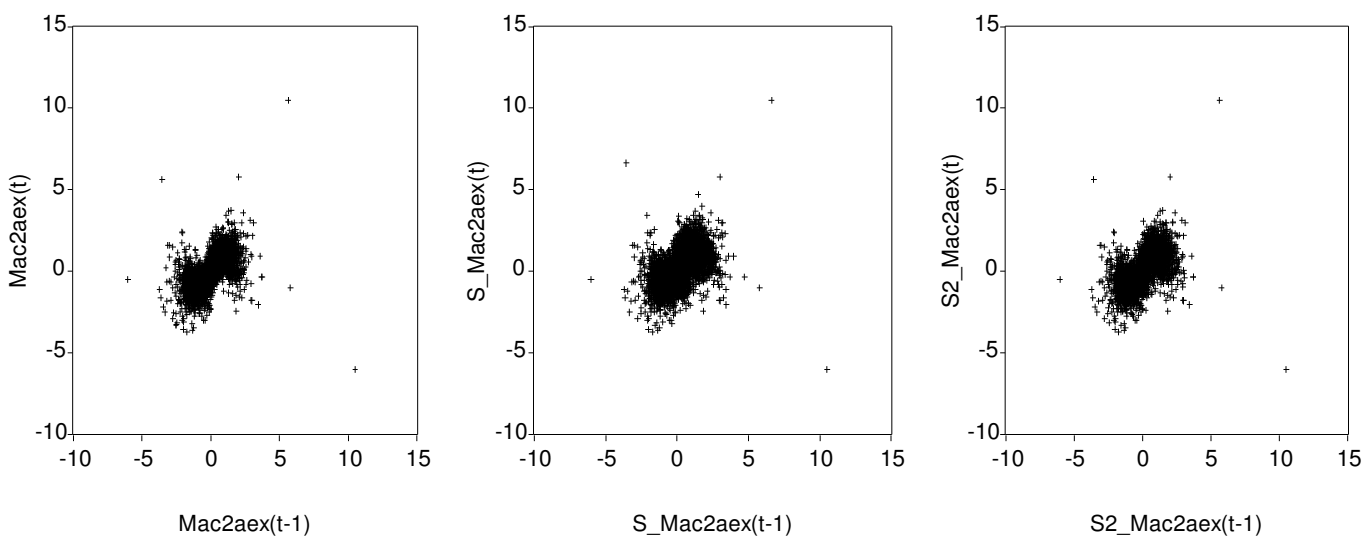

Figures 12a,b,c: Attractors of the Mac2aex model with and without information signals 

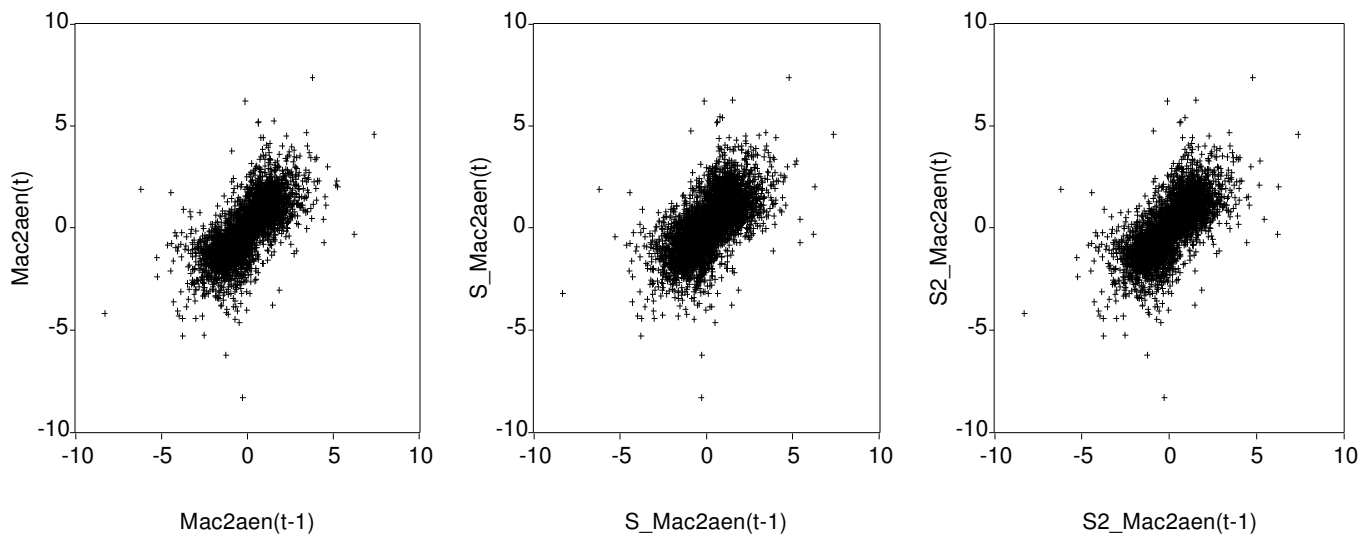

Figures 13a,b,c: Attractors of the Mac2aen model with and without information signals 
Table 2: Estimation results for simulated series

\begin{tabular}{|c|c|c|c|c|c|c|c|c|c|c|c|}
\hline \multirow{2}{*}{ Models } & \multicolumn{9}{|c|}{ Mean Equation } & \multicolumn{2}{|c|}{ Variance Equation } \\
\hline & $\phi_{1}$ & b & $\alpha$ & $\delta$ & $\mathbf{D}_{1}$ & $\mathbf{D}_{2}$ & $\mathbf{D}_{3}$ & $\mathbf{D}_{4}$ & $\mathbf{D}_{5}$ & $\mathbf{a}_{0}$ & $\mathbf{a}_{1}$ \\
\hline$A R(1)$ & $\frac{0.4849}{(36.395)}$ & & & & & & & & & & \\
\hline$S \_A R(1)$ & $\frac{0.4881}{(36.208)}$ & & & & $\underline{1.003}$ & $\frac{-0.546}{(-14.243)}$ & $\begin{array}{l}-0.04178 \\
(-1.2236)\end{array}$ & $\begin{array}{l}-0.00137 \\
(-0.0378)\end{array}$ & $\frac{-0.082526}{(-2.3857)}$ & & \\
\hline$S 2 \_A R(1)$ & $\underline{0.4728}$ & & & & $\frac{0.2286}{(5.9796)}$ & $\frac{-0.1667}{(-4.4914)}$ & $\begin{array}{c}-0.043 \\
(-1.2594)\end{array}$ & $\begin{array}{c}-0.002615 \\
(-0.071985)\end{array}$ & $\frac{-0.08315}{(-2.4048)}$ & & \\
\hline $\log E q N$ & & $\frac{3.8}{(4359.11)}$ & & & & & & & & & \\
\hline$S \_L o g E q N$ & & $\frac{0.5158}{(27.647)}$ & & & $\frac{1.54955}{(185.976)}$ & $\frac{1.2081}{(44.657)}$ & $\frac{0.5376}{(62.8014)}$ & $\underline{0.5484}$ & $\frac{0.551176}{(65.84104)}$ & & \\
\hline$S 2 \_L o g E q N$ & & $\underline{0.273}$ & & & $\frac{0.81729}{(48.225)}$ & $\frac{0.670126}{(71.93129)}$ & $\frac{0.577427}{(64.45429)}$ & $\frac{0.58894}{(67.339)}$ & $\frac{0.591922}{(67.76205)}$ & & \\
\hline $\operatorname{Mac} 2 n$ & & & $\frac{2.1987}{(31.7397)}$ & $\frac{0.0629}{(2.9057)}$ & & & & & & & \\
\hline$S \_M a c 2 n$ & & & $\frac{1.65712}{(23.3419)}$ & $\frac{-0.1103}{(-4.9443)}$ & $\underline{0.9731}$ & $\frac{-0.49209}{(-11.389)}$ & $\begin{array}{c}0.032529 \\
(0.96938)\end{array}$ & $\begin{array}{c}-0.005253 \\
(-0.149536)\end{array}$ & $\begin{array}{c}-0.006756 \\
(-0.1971)\end{array}$ & & \\
\hline$S 2 \_M a c 2 n$ & & & $\frac{2.0601}{(28.997)}$ & $\begin{array}{c}0.0277 \\
(1.2629)\end{array}$ & $\frac{0.203690}{(5.5198)}$ & $\frac{-0.1117}{(-3.0165)}$ & $\begin{array}{c}0.02726 \\
(0.81675)\end{array}$ & $\begin{array}{c}-0.002723 \\
(-0.0781)\end{array}$ & $\begin{array}{c}-0.008588 \\
(-0.25216)\end{array}$ & & \\
\hline Mac2aex & & & $\frac{2.109}{(46.2048)}$ & $\frac{0.0545}{(2.7101)}$ & & & & & & $\underline{0.2059}$ & $\frac{0.57869}{(17.184)}$ \\
\hline S_Mac2aex & & & $\frac{1.3095}{(24.714)}$ & $\frac{-0.3161}{(-13.0865)}$ & $\frac{0.9549}{(46.4878)}$ & $\frac{-0.6503}{(-23.1798)}$ & $\begin{array}{c}-0.009956 \\
(-0.4961)\end{array}$ & $\begin{array}{c}0.007216 \\
(0.3743)\end{array}$ & $\begin{array}{c}0.001756 \\
(0.0944)\end{array}$ & $\frac{0.2829}{(27.992)}$ & $\frac{0.498}{(13.73)}$ \\
\hline S2_Mac2aex & & & $\frac{2.0465}{(38.863)}$ & $\begin{array}{c}0.0213 \\
(0.9294) \\
\end{array}$ & $\frac{0.182}{(7.8138)}$ & $\frac{-0.0766}{(-3.7242)}$ & $\begin{array}{c}-0.018859 \\
(-1.02258)\end{array}$ & $\begin{array}{l}0.00433 \\
(0.2422)\end{array}$ & $\begin{array}{c}0.0108 \\
(0.5734)\end{array}$ & $\frac{0.2642}{(27.6397)}$ & $\frac{0.5244}{(15.118)}$ \\
\hline Mac10n & & & $\frac{2.161}{(48.6012)}$ & $\frac{0.0327}{(2.3835)}$ & & & & & & & \\
\hline S_Mac10n & & & $\frac{1.5622}{(29.2282)}$ & $\frac{-0.0592}{(-4.10217)}$ & 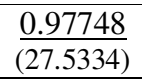 & $\frac{-0.2922}{(-5.264464)}$ & $\begin{array}{r}0.0193 \\
(0.5353) \\
\end{array}$ & $\begin{array}{l}0.01538 \\
(0.4289) \\
\end{array}$ & $\begin{array}{r}0.0536 \\
(1.4908) \\
\end{array}$ & & \\
\hline S2_Maclon & & & $\frac{2.0495}{(42.446)}$ & $\begin{array}{c}0.0152 \\
(1.0999)\end{array}$ & $\frac{0.21572}{(5.6801)}$ & $\begin{array}{l}-0.06209 \\
(-1.5215)\end{array}$ & $\begin{array}{l}0.02026 \\
(0.5726)\end{array}$ & $\begin{array}{l}0.01817 \\
(0.5164)\end{array}$ & $\begin{array}{l}0.0539 \\
(1.519)\end{array}$ & & \\
\hline MaclOa & & & $\frac{2.1115}{(93.4907)}$ & $\underline{0.0548}$ & & & & & & $\frac{0.2019}{(27.138)}$ & $\frac{0.5779}{(17.34)}$ \\
\hline S_Mac10a & & & $\frac{1.39797}{(36.5165)}$ & $\frac{-0.1728}{(-10.3816)}$ & $\frac{1.0265}{(40.9048)}$ & $\frac{-0.3787}{(-8.6863)}$ & $\begin{array}{l}0.03146 \\
(1.2927)\end{array}$ & $\begin{array}{l}-0.00788 \\
(-0.3624)\end{array}$ & $\frac{0.0407}{(1.8674)}$ & $\frac{0.5353}{(28.1578)}$ & $\frac{0.2984}{(8.9877)}$ \\
\hline S2_Mac10a & & & $\frac{2.0049}{(72.49)}$ & $\frac{0.0203}{(1.7462)}$ & $\frac{0.08926}{(3.38175)}$ & $\begin{array}{c}-0.0387 \\
(-1.6686)\end{array}$ & $\begin{array}{c}0.0234 \\
(1.3035)\end{array}$ & $\begin{array}{l}-0.00042 \\
(-0.02415)\end{array}$ & $\frac{0.04028}{(2.0288)}$ & $\frac{0.2873}{(21.7265)}$ & $\underline{\underline{0.54704}}$ \\
\hline
\end{tabular}

*t-statistic is given within parenthesis. Underlined values are significant. We note that White Heteroskedasticity-Consistent standard errors and covariance as well as

Bollerslev-Wooldrige robust standard errors and covariance are used. 


\section{References}

Balke, N., and Fomby, T., 1994. Large shocks, small shocks, and economic fluctuations: outliers in macroeconomic time series, Journal of Applied Econometrics, 9, pp. 181-200.

Beller, K., and Nofsinger, J.R., 1998. On stock return seasonality and conditional heteroskedasticity, The Journal of Financial Research, 21, No.2, pp. 229-246.

Bernhardt, D., Campello, D., and Kutsoati E., 2006. Who herds, Journal of Financial Economics, 80, pp. 657-676.

Bollerslev, T., and Ghysels, E., 1996. Periodic autoregressive conditional heteroskedasticity, Journal of Business and Economic Statistics, 14, No 2, pp. 139-152.

Burridge, P., and Taylor, A.M.R., 1999. On regression-based tests for seasonal unit roots in the presence of periodic heteroskedasticity, Discussion Paper, No. 9910, Department of Economics, University of Birmingham.

Corazza, M., and Malliaris A.G., 2002 Multi-fractality in foreign currency markets, Multinational Finance Journal, 6, pp. 65-98.

Corazza, M., Malliaris, A.G., and Nardelli C., 1997. Searching for fractal structure in agricultural futures markets, Journal of Futures Markets, 17, pp. 433-473.

Cutler, D.M., Poterba, J.M., and Summers, L.H., 1989. What moves stock prices?, Journal of Portfolio Management, April, pp. 4-12.

Franke, R., and Sethi, R., 1998. Cautious trend-seeking and complex asset price dynamics, Research in Economics, 52, pp. 61-79.

Franses, P., Van Dijk, D., and Lucas, A., 2004. Short patches of outliers, ARCH and volatility modelling, Applied Financial Economics, 14, pp. 221-231.

Hirshleifer, D., Subrahmanyam A., and Titman S., 2006. Feedback and the success of irrational investors, Journal of Financial Economics, 81, pp. 311-338.

Hristu-Varsakelis, D., and Kyrtsou, C., 2008. Evidence for nonlinear asymmetric causality in US inflation, metal and stock returns, Discrete Dynamics in Nature and Society, to appear.

Kent, D., and Titman, S., 2006. Market reactions to tangible and intangible information, The Journal of Finance, 61, pp. 1605-1643. 
Kurz, M.,Jin H. and Motolese, M. 2003. The role of expectations in economic fluctuations and the efficacy of monetary policy, working paper, Department of Economics, Stanford University. Kyrtsou, C., 2005a. Studying the relationship between prices and fundamental value in an artificial market framework, Unpublished Manuscript, University of Macedonia, Thessaloniki, Greece.

Kyrtsou, C., 2005b. Evidence for neglected linearity in noisy chaotic models, International Journal of Bifurcation and Chaos, 15, 10, pp. 3391-3394.

Kyrtsou, C., 2006. Heterogeneous non-linear trading rules and routes to chaotic dynamics, forthcoming Working Paper, LAMETA, University of Montpellier I.

Kyrtsou, C., and Terraza, M., 2002. Stochastic chaos or ARCH effects in stock series ? A comparative study, International Review of Financial Analysis, 11, pp 407-431.

Kyrtsou, C., and Terraza, M., 2003. Is it possible to study chaotic and ARCH behaviour jointly? Application of a noisy Mackey-Glass equation with heteroskedastic errors to the Paris Stock Exchange returns series, Computational Economics, 21.

Kyrtsou, C., and Terraza, V., 2008. Value-at-Risk, outliers and chaotic dynamics, Proceedings of the $3^{\text {rd }}$ International Conference on Computational Finance, WIT press, Southampton, Boston.

Kyrtsou, C. and W. Labys, 2006: Evidence for chaotic dependence between US inflation and commodity prices, Journal of Macroeconomics, vol. 28, 1, 256-266.

Kyrtsou, C. and W. Labys, 2007. Detecting positive feedback in multivariate time series: the case of metal prices and US inflation, Physica A, vol. 377, 1, 227-229.

Kyrtsou, C., Labys, W., Terraza, M., 2004: Noisy chaotic dynamics in commodity markets, Empirical Economics, 29 (3), pp. 489-502.

Kyrtsou, C., Leontitsis A., and Siriopoulos C., 2006. Exploring the impact of calendar effects on the dynamic structure and forecasts of financial series, International Journal of Theoretical and Applied Finance, 9, 1, 1-22.

Kyrtsou, C. and A. Serletis, 2006, Univariate tests for nonlinear structure, Journal of Macroeconomics, 28, 1, 154-168. 
Kyrtsou, C., and Vorlow, C., 2005. Complex dynamics in macroeconomics: A novel approach, in New Trends in Macroeconomics, Diebolt, C., and Kyrtsou, C., (eds.), Springer Verlag. Kyrtsou, C., and Vorlow, C., 2009. Modelling nonlinear comovements between time series, Journal of Macroeconomics, to appear.

Lee, W., Jiang, C., and Indro, D., 2002. Stock market volatility, excess returns, and the role of investor sentiment, Journal of Banking \& Finance, 26, pp. 2277-2299.

Malliaris, A.G., and Stein, J.L., 1999. Methodological issues in asset pricing: random walk or chaotic dynamics, Journal of Banking \& Finance, 23, pp. 1605-1635.

Shefrin, H., and Statman, M., 1994. Behavioural Capital Asset Pricing Theory, Journal of Financial and Quantitative Analysis, 29, No. 3, pp. 323-349.

Van Dijk, D., Franses, P., and Lucas, A., 1999. Testing for ARCH in the presence of additive outliers, Journal of Applied Econometrics, 14, pp. 539-562.

Vega, C., 2006. Stock price reaction to public and private information, Journal of Financial Economics, 82, pp. 103-133.

Yang, J.-H., and Satchell S., 2003 The impact of technical analysis on asset price dynamics, Working Paper, Faculty of Economics and Politics and Trinity College, University of Cambridge. 